\title{
Colopleural fistula due to strangulated Bochdalek hernia in an adult
}

\author{
M SINHA, P GIBBONS, S C KENNEDY, H R MATTHEWS \\ From the Departments of General Surgery and Thoracic Surgery, East Birmingham Hospital, Birmingham
}

\begin{abstract}
An elderly patient presented with a right sided pneumothorax due to strangulation of part of the colon through a congenital Bochdalek hernia. Congenital posterolateral diaphragmatic hernia of Bochdalek is rare in an adult and strangulation with pneumothorax has not been reported before.
\end{abstract}

Congenital diaphragmatic hernia is more often diagnosed in infants than in adults, in whom it usually presents with gastrointestinal symptoms. Pneumothorax due to strangulated diaphragmatic hernia is very rare, and we report the first case of a pneumothorax caused by a colopleural fistula through such a hernia.

\section{Case report}

A 70 year old woman was admitted to a local hospital as an emergency in February 1986 with a history of intermittent upper abdominal and right sided chest pain of several months' duration and shortness of breath of a week's duration. On examination she had a raised temperature and a respiratory rate of $56 / \mathrm{min}$. There were signs of a right tension pneumothorax with the trachea shifted to the left; percussion note, breath sounds, and tactile vocal fremitus were diminished at the right base. Abdominal examination showed right hypochondrial tenderness only. A chest radiograph (fig 1) showed a right hydropneumothorax and the displaced trachea. The haemoglobin concentration was $11 \cdot 1 \mathrm{~g} / \mathrm{dl}$ and the white cell count $15.2 \times 10^{9} / 1$ with neutrophil leucocytosis.

A right intercostal drain was inserted by the dissection technique and connected to an underwater seal. This allowed the drainage of foul smelling faeculent fluid, which grew Escherichia coli, Pseudomonas aeruginosa, and Bacteroides spp on culture. The patient was treated with antibiotics (metronidazole, gentamicin, and mezlocillin) and transferred to the regional thoracic surgical unit.

Over the next five days large volumes of faecal fluid continued to drain. The white cell count continued to rise and the haemoglobin concentration fell to $9.0 \mathrm{~g} / \mathrm{dl}$. The patient was given a blood transfusion and a barium swallow was performed. This showed no oesophageal or gastric perforation or hiatal hernia. An ultrasonic scan of the right subphrenic area showed a normal liver and no evidence of a fluid collection. Two days later a fistulogram (fig 2) showed barium within the ascending colon; the hepatic flexure was seen to be above the liver and barium leaked into the pleural cavity. Her primary disease was thought to be probably in the

Address for reprint requests: Mr M Sinha, Department of General Surgery, East Birmingham Hospital, Birmingham B9 5ST.

Accepted 13 April 1989

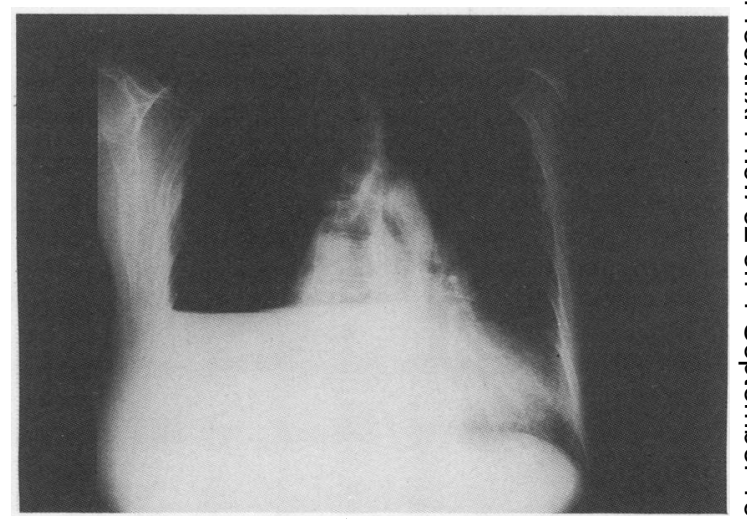

Fig 1 Radiograph showing right tension hydropneumothorax.

colon (possibly neoplastic) with perforation across the diaphragm into the chest. Elective laparotomy was performed a week later. The hepatic flexure was found to have passed anterior to the liver and was firmly attached to the diaphragm in the right superior subphrenic space. The mid ascending colon was divided to form a double barrelled colostomy, the lower opening being an end colostomy and the upper a mucous fistula to prevent the formation of a closed loop superiorly. The chest drain was left undisturbed.

Over the next few weeks the fluid from the thoracic drain diminished and the lung expanded fully, allowing the drain to be removed. The patient's general condition improved considerably, so a further laparotomy was carried out a $\overline{0}$ month after the first. The right colon just distal to the mucous fistula was seen to be passing through a $3 \times 3 \mathrm{~cm}$ defect in the $\delta$ posterolateral part of the right diaphragm. The edges of the defect were smooth and uninflamed, and had the characteristics of a Bochdalek type of congenital diaphragmatic hernia. A knuckle of transverse colon had gone through the hernia $D$ and become gangrenous. This segment of the colon was resected (along with the mucous fistula) and the distal end $N$ closed and dropped inside with a view to joining this end to $G$ the proximal end colostomy at a later stage. A size 32 Argyle $N$ chest drain was inserted from below through the dia- $N$ phragmatic defect and connected to an underwater seal. The hole in the diaphragm was closed with interrupted Merselene sutures. After one week the chest drain was disconnected from the underwater seal and progressively shortened. The $\mathbb{D}$ empyema space had completely closed by the end of the second week. The patient was discharged two days later.

She continued to make good progress and six months later was admitted for closure of the colostomy by joining the end $\mathbb{D}$ colostomy to the closed end of the distal (transverse) colon. She made an uncomplicated recovery and was discharged 10 

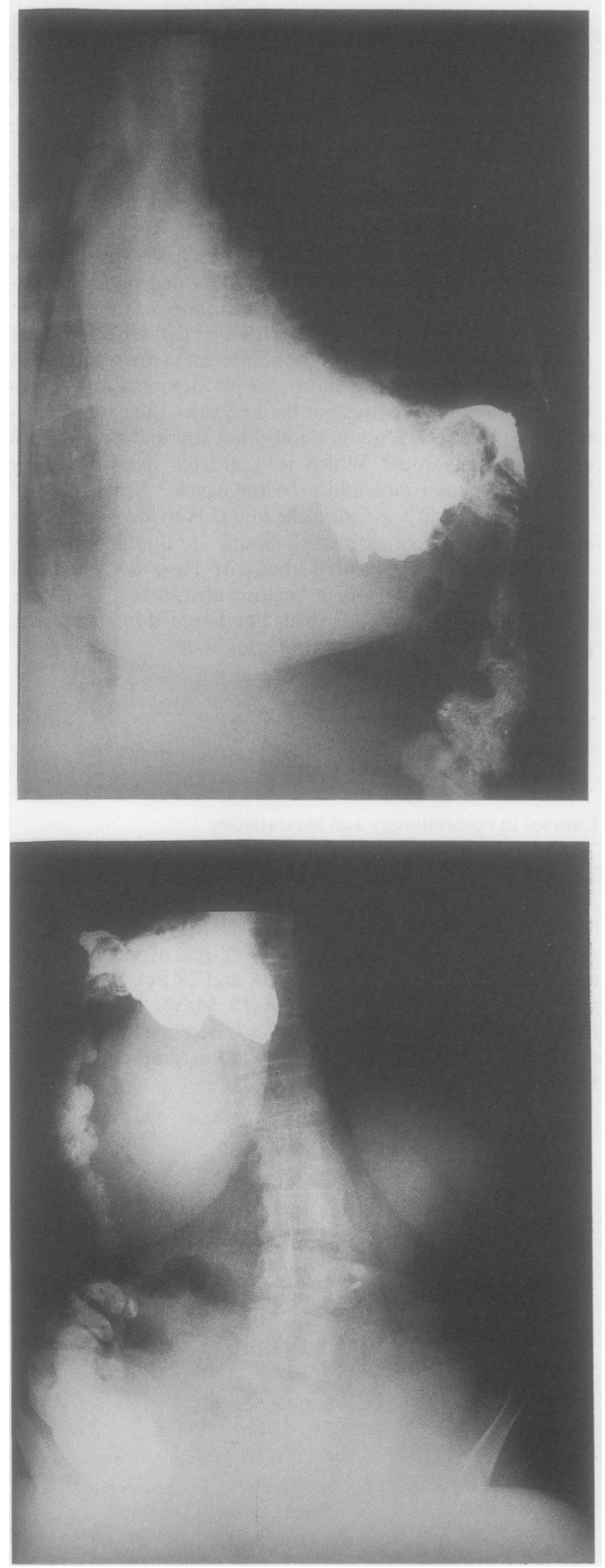

Fig 2 Fistulogram showing barium leaking into the ascending colon in the chest. days after her operation. She was well when seen as an outpatient two months later.

\section{Discussion}

The diaphragm is formed by the septum transversum anteriorly, the lateral body wall and the pleuroperitoneal membranes laterally, and the dorsal body wall and the dorsal mesogastrium posteriorly. Fusion of these elements in the seventh or eighth week of embryonic life ${ }^{1}$ normally closes the pleuroperitoneal canal. Failure of the pleuroperitoneal membranes to close allows the formation of a congenital diaphragmatic hernia of Bochdalek.

The prevalence of Bockdalek hernia in adults has been disputed. ${ }^{2}$ Most cases are diagnosed in the neonatal period, clinical features being related to the respiratory system, unlike the usual adult presentation with gastrointestinal symptoms. $^{34}$

Kirkland ${ }^{5}$ in 1959 found 34 reported cases of Bochdalek hernia in adults. In 1983 Hines $^{6}$ reviewed a further 19 adult cases of congenital diaphragmatic hernia and reported a case of his own; the reported figure of Bochdalek hernia in adults stands around 90 . None of these has had a fistula between the gastrointestinal tract and either pleural cavity.

Our review of published reports found three other cases of pneumothorax due to strangulated diaphragmatic hernia. Two of these cases were in children, in whom incarceration of the stomach in a Bochdalek hernia was followed by the development of gastropleural fistula and pneumothorax. ${ }^{78}$ The other case was an adult with a left sided pneumothorax due to colopleural fistula through a strangulated traumatic diaphragmatic hernia. ${ }^{9}$ Thus our patient is the first reported with a pneumothorax due to colopleural fistula through a strangulated congenital diaphragmatic hernia of Bochdalek.

Initial diagnosis in our patient was difficult. Sinography revealed the diagnosis. A barium enema would also have been diagnostic. Colopleural fistula of this kind should be treated in stages. Primary resection and anastomosis could not be attempted in view of patient's poor health and sepsis from faecal contamination. Great care should be taken to improve the patient's health and control the sepsis before definitive closure of the colostomy.

\section{References}

1 Langman J. Medical embryology. 3rd ed. Baltimore: Williams and Williams, 1975:307.

2 Gale ME. Bochdalek hernia: prevalence and CT characteristics. Radiology 1985;156:449-52.

3 Sugg WL, Roper CL, Carlsonn E. Incarcerated Bochdalek hernia in the adult. Am J Surg 1964;160:847-51.

4 Powers RC, Sejdinaj I, Paul B. Oberschneider: strangulated foramen of Bochdalek hernia in the adult. Am J Surg 1966;3:749-51.

5 Kirkland JA. Congenital posterolateral diaphragmatic hernia in the adult. Br J Surg 1959;47:16-21.

6 Hines GL, Romero C. Congenital diaphragmatic hernia in the adult. Int Surg 1983;68:349-51.

7 Hermann RE, Barber DH. Congenital diaphragmatic hernia in the child beyond infancy. Cleveland Clinical Quarterly 1963;30: 73-80.

8 Spinola SM, Ingram DL, Cerwin RA, Denny FW. Pneumothorax in a 14 year old boy. $J$ Pediatr 1981;98:328-32.

9 Radin DR, Ray MJ, Halls JM. Strangulated diaphragmatic hernia with pneumothorax due to colopleural fistula. $A J R$ 1986;146:321-2. 